\title{
Plano de carreira profissional da educação básica em Minas Gerais: valorização profissional ${ }^{1}$
}

\author{
Vera Lúcia Ferreira Alves de Brito ${ }^{2}$ \\ veraluciabrito@ig.com.br
}

\begin{abstract}
Resumo
O estudo tem como objetivo analisar as políticas de educação no contexto brasileiro e a configuração e desenvolvimento de carreira dos professores da educação básica do Estado de Minas Gerais. Com base nas normas legais e no plano de carreira, são investigadas as políticas de valorização desses profissionais no Estado de Minas Gerais. O plano de carreira dos profissionais da educação foi criado pela Lei n. 15.293, promulgada em 2004, e inclui classes e níveis que permitem conhecer a estrutura da carreira. Em 2010, a Lei n. 18.975 fixou a remuneração dos profissionais da educação básica sob a forma de Subsídio vedando o acréscimo de qualquer gratificação, adicional, abono, prêmio, verba de representação ou outra espécie remuneratória, na perspectiva da administração gerencial do Estado de Minas Gerais, denominada 'choque de gestão'. A pesquisa situa-se no contexto das políticas públicas de financiamento da educação.
\end{abstract}

Palavras-chave: Legislação; Políticas educacionais; Remuneração de professores.

1 Este artigo contou com a colaboração da professora Maria da Consolação Rocha e dos bolsistas Daniel Santos Braga e Franceline Rodrigues da Silva.

2 Doutora em Educação pela Universidade Federal de Minas Gerais (1995). Professora da Universidade do Estado de Minas Gerais. 


\section{Introdução}

O objetivo deste trabalho é analisar o plano de carreira dos profissionais da educação básica de Minas Gerais como um elemento fundamental para a construção de uma política de Estado destinada à valorização não apenas dos profissionais, mas de toda escola pública. Nesse enfoque, considera-se que as políticas educacionais traduzem, sempre, um campo de lutas com prioridades e valores diversos. Desse modo, a correlação de força existente prioriza valores e concepções que se tornam normas em vigor.

A valorização dos profissionais da educação, estabelecida pela Constituição Federal de 1988, foi decisiva para o delineamento de um novo momento para a profissão docente e nos remete a fazer referência aos movimentos desses profissionais que, neste trabalho, restringem-se aos limites do território de Minas Gerais. No caso mineiro, o Plano de Carreira dos Profissionais da Educação Básica do Estado resulta tanto das normatizações federais sobre a carreira, como da conjuntura políticoeconômica estabelecida a partir de 2003.

O Plano de Carreira dos Profissionais da Educação Básica do Estado de Minas Gerais, instituído pela Lei n. 15.293 (MINAS GERAIS, 2004), está fundamentado nas diretrizes da Resolução n. 3/97, do Conselho Nacional de Educação (CNE), e inclui o ingresso na carreira por concurso público de provas e títulos; a qualificação mínima referente ao ensino médio completo, na modalidade normal, para a docência na Educação Infantil e para as quatro primeiras séries do Ensino Fundamental; ensino superior em curso de licenciatura, de graduação plena, com habilitações específicas em área própria, para a docência nas séries finais do Ensino Fundamental e para o Ensino Médio; formação superior em área correspondente para a docência em áreas específicas das séries finais do Ensino Fundamental e do Ensino Médio.

A Resolução n. 3/97 (BRASIL, 1997) inclui a necessidade dos sistemas de ensino envidarem esforços para implementar programas de desenvolvimento profissional dos docentes em exercício, incluída a formação em nível superior, em instituições credenciadas, bem como 
em programas de aperfeiçoamento em serviço. Assegura 45 dias de férias anuais e define que a jornada de trabalho dos docentes poderá ser de até 40 horas, incluindo de 20 a $25 \%$ de horas de atividades. Considera horas de atividades aquelas destinadas à preparação e avaliação do trabalho didático, à colaboração com a administração da escola, às reuniões pedagógicas, à articulação com a comunidade e ao aperfeiçoamento profissional, de acordo com a proposta pedagógica de cada escola.

Quanto à remuneração dos docentes, afirma que deverá contemplar níveis de titulação, sem que a atribuída aos portadores de diploma de licenciatura plena ultrapasse em mais de $50 \%$ à que couber aos formados em nível médio. Estabelece que poderão ser considerados incentivos de progressão por qualificação de trabalho docente: a dedicação exclusiva ao cargo, no sistema de ensino; o desempenho no trabalho, mediante avaliação segundo parâmetros de qualidade do exercício profissional, a serem definidos em cada sistema; a qualificação em instituições credenciadas; o tempo de serviço na função docente. São previstas, ainda, avaliações periódicas de aferição de conhecimentos na área curricular em que o professor exerça a docência e de conhecimentos pedagógicos.

A remuneração dos docentes do Ensino Fundamental deverá ser definida em uma escala cujo ponto médio terá como referência o custo médio aluno-ano, para uma jornada 20 horas de aula e 05 horas de atividades, e diferenciada segundo jornada maior e menor.

\section{A conjuntura econômico-política e o Plano de Carreira}

A nova política administrativa do Estado de Minas iniciou-se em janeiro de 2003, apresentando um projeto de reforma com vistas à suplantação do modelo de administração pública anterior. Para isto, empreendeu-se a reestruturação orgânica do Poder Executivo, segundo um novo modelo gerencial, com a edição de 63 leis delegadas, visando respostas rápidas e eficientes às demandas do setor público. Empregouse o paradigma da Administração Pública voltada para resultados, fundamentada na qualidade e na eficiência. O Secretário de Estado de Planejamento e Gestão explicitou: 
O Estado deve imbuir-se efetivamente de uma maior responsabilidade na gestão fiscal, conforme determinado pela Lei Complementar Federal n. ${ }^{\circ}$ 101, de 4 de maio de 2000, buscando corrigir o desequilíbrio de suas contas públicas e reduzir o déficit que ameaça o exercício de suas atividades. Faz-se necessário, pois, impor limites e condições à geração de maiores despesas com pessoal, seguridade social, materiais, dentre outras, bem como à renúncia de receita (ANASTASIA, 2003).

No contexto dessa política de ajuste fiscal implementada pela administração estadual, buscou-se, neste trabalho, analisar os efeitos da mesma na carreira do professor de educação básica estadual e, também, analisar a resistência do movimento dos professores. Na implementação desse modelo paradigmático de Administração Pública, o indicador da despesa com pessoal foi o primeiro e principal alvo em que foram utilizados artifícios contábeis para demonstrar o seu enquadramento às novas regras.

\section{Explicitação teórica acerca das negociações sindicais}

A transformação das associações em sindicatos únicos, por categoria, a separação dos níveis educativos, a separação por associações de dirigentes e a exclusão dos trabalhadores e auxiliares de serviços das entidades docentes, são características que podem ser consideradas como identificadoras da especificidade do movimento de professores no Brasil. A Constituição de 1988 (BRASIL, 1988) ratificou a proibição de serem criados mais de um sindicato da categoria, por município, regra que vigora desde a década de 1930, proibição que vem sendo anulada através de sentenças judiciais nos últimos anos. Todas essas limitações afetaram diretamente a organização sindical e, principalmente, a proibição de sindicalização de funcionários públicos que vigorou até 1988. O marco jurídico atual, ao normatizar o direito sindical, origina o direito de negociação que, em princípio, deveria ser coletiva e que, na realidade, não avançou na contratação coletiva, mas apenas na extensão a toda a categoria dos resultados das negociações. O exemplo do México 
é significativo, pois mostra uma situação oposta: a Lei Geral de Educação ratifica o sindicato como titular do contrato coletivo de trabalho, participando em condições de paridade com a autoridade governamental sobre as condições trabalhistas docentes em âmbito nacional.

No Brasil, a participação dos sindicatos de docentes não tem sido reconhecida na definição e implantação das políticas públicas educacionais, embora admitida sua participação em negociações trabalhistas. Apesar da atuação dos professores primários ter sido significativa desde 1930, houve uma inflexão relevante na organização do magistério, com a criação da União dos Trabalhadores do Ensino (UTE), em 1979, tendo se transformado em sindicato em 1998 (Sind-UTE). O alijamento quanto ao planejamento educacional e quanto à formulação de políticas educacionais restringiu os sindicatos às lutas por reivindicações salariais. A reivindicação por Plano de Carreira insere os sindicatos de professores numa lógica coletiva diferente da tradição corporativista e individualista, ampliando as ações sindicais para um movimento coletivo de valorização e consolidação profissional dos docentes.

A pesquisa sobre o embate entre movimentos docentes e gestores governamentais visou captar interesses e concepções diferenciados, enfatizando a abordagem teórica que concebe a formulação de políticas públicas como campo de lutas políticas. A investigação realizada sobre as greves e as pautas reivindicatórias dos professores da rede estadual de Minas Gerais permitiu perceber os conflitos que se tornaram relevantes para a percepção desse campo de lutas políticas. Concebeu-se, desse modo, que uma negociação indica condições propícias ao diálogo na esfera pública, no qual se explicitam as enunciações, embora essa relação não signifique consenso, mas confronto entre posições diferenciadas sobre a educação e sobre o trabalho docente. Apesar do empenho dos movimentos de professores em se constituírem como organização independente e autônoma, as tensas relações com a administração pública são frequentemente perpassadas por conflitos em que pautas diferenciadas e, também, posições político-partidárias interferem de modo significativo nas negociações.

Com relação às questões relativas à remuneração, o aspecto conflitivo 
da negociação aparece com nitidez, pois se trata de um embate travado entre reivindicações de funcionários públicos por plano de carreira profissional e salário digno, por um lado, e órgãos estatais superiores, responsáveis pelo pagamento e pelo enquadramento, por outro; conflito esse que transcorre em torno dos interesses e pautas que cada uma das partes elabora, incidindo, seu resultado, diretamente sobre a remuneração docente.

A submissão das demandas aos órgãos administrativos e fazendários demarca os limites mínimos e máximos do acolhimento às reivindicações, num cenário de ajuste fiscal e de políticas administrativas voltadas para a eficácia. Desse modo, de antemão, estão explicitadas as condições de distribuição desigual de postos de trabalho e de sua remuneração, dependentes das concepções sobre a importância de políticas sociais e educacionais do grupo governante.

A pesquisa de campo analisou os documentos sobre movimentos dos professores, em Minas Gerais, em vários momentos em que a negociação foi realizada; compara as pautas de reivindicações de movimentos grevistas e seu provável efeito nas regulações do trabalho docente e na tramitação da lei que aprovou o Plano de Carreira do magistério público estadual.

\section{A reivindicação dos profissionais da educação por plano de carreira}

A reivindicação por um plano de carreira é antiga em Minas Gerais e, no final da década de 1990, havia sido objeto de sucessivas greves (14 dias, em1999, e 42 dias em 2000). Em 2002, após 50 dias de greve, o Governo do Estado firmou documento de Ajuste de Conduta com o Ministério Público, em decorrência de reivindicação do Sindicato dos Trabalhadores em Educação (Sind-UTE), concordando em enviar à Assembleia Legislativa do Estado de Minas Gerais o Plano de Carreira que, depois de debatido, foi aprovado em 2004. Foram instituídas oito Carreiras dos Profissionais de Educação Básica do Estado:

a) Professor de Educação Básica - PEB; b) Especialista em Educação Básica - EEB; c) Analista de Educação Básica - AEB; d) Assistente Técnico de Educação 
Básica - ATB, com atuação nas unidades escolares. As outras carreiras: Assistente Técnico Educacional - ATE; Analista Educacional - ANE; Assistente de Educação - ASE; Auxiliar de Serviços de Educação Básica - ASB têm atuação prevista na Secretaria de Educação, Superintendências Regionais da SEE, no Conselho Estadual de Educação e outros órgãos. (MINAS GERAIS, 2004).

A carreira do professor de Educação Básica manteve vários pontos do Estatuto do Magistério, de 1977, quanto ao ingresso por concurso de provas e títulos, a jornada docente e a promoção por titulação. $\mathrm{O}$ texto aprovado em 2004 reitera o ingresso por aprovação em concurso público de provas ou de provas e títulos e a primeira inserção dar-se-á, conforme determina o art. 11, no primeiro grau do nível correspondente à escolaridade exigida (MINAS GERAIS, 2004). Os níveis mínimos de habilitação exigidos para o ingresso na carreira são:

I - para a carreira de Professor de Educação Básica: I) habilitação específica obtida em curso de magistério de nível médio de escolaridade, para ingresso no nível I;

II) habilitação específica obtida em curso superior com licenciatura de curta duração, para ingresso no nível II;

III) habilitação específica obtida em curso superior com licenciatura plena ou graduação com complementação pedagógica, para ingresso no nível III;

IV) habilitação específica obtida em curso superior com licenciatura plena ou graduação com complementação pedagógica, acumulada com mestrado em educação, ou em área afim, para ingresso no nível IV;

V) habilitação específica obtida em curso superior com licenciatura plena ou graduação com complementação pedagógica, acumulada com doutorado em educação, ou em área afim, para ingresso no nível V. (MINAS GERAIS, 2004).

Portanto, para a Carreira do Professor de Educação Básica, mantém-se o nível médio para o ingresso, exigência mínima para os professores da Educação Infantil e dos anos iniciais do Ensino Fundamental. Por sua vez, 
a escolaridade adicional foi considerada uma conquista, pois a titulação superior à exigida pela função pode antecipar a promoção, reduzindo o tempo de 5 anos exigido. Porém, a promoção por escolaridade adicional não é automática e deve passar por aprovação da Câmara de Coordenação-Geral da Secretaria de Planejamento, Gestão e Finanças (SEPLAG), conforme disposto no art. 22 da Lei.

A Lei n. 15.293/04 estabelece que os cargos de Secretário de Escola e Diretor de Escola são cargos comissionados, esse último com jornada de trabalho de 40 horas. Com referência à direção, nas escolas de Educação Infantil e Ensino Fundamental com até quatro turmas, a direção será exercida por professor, sem afastamento da regência, como Coordenador da Escola. Este receberá 10\% do vencimento básico, por turma existente (MINAS GERAIS, 2004).

A carga horária semanal do Professor é de 24 horas, sendo dezoito horas destinadas à docência e seis horas destinadas a reuniões e outras atribuições e atividades específicas do cargo. A carga horária do Professor de Educação Básica não poderá ser reduzida, salvo na ocorrência de remoção e de mudança de lotação.

O vencimento básico do Professor de Educação Básica dos anos finais do Ensino Fundamental e do Ensino Médio é proporcional ao número de horas semanais fixadas para o cargo e poderá haver extensão da jornada de até dezoito horas-aula, para que seja ministrado conteúdo curricular para o qual o professor seja habilitado ou que esteja autorizado a lecionar, remuneradas com valor adicional proporcional ao valor do vencimento básico. No caso do servidor ocupante de dois cargos de Professor de Educação Básica, poderá haver extensão da jornada até o máximo de trinta e seis horas, excluídas desse total as aulas assumidas por exigência curricular.

Com relação aos níveis e graus que compõem a carreira, os Professores da Educação Básica têm cinco Níveis (I a V) para promoção na carreira e quinze Graus (A a P) para a progressão horizontal. Para a progressão exigem-se dois anos de exercício e duas avaliações de desempenho individual satisfatórias. Já a promoção, que é a passagem do servidor de um nível para o imediatamente superior, dependerá do cumprimento 
de 5 anos de efetivo exercício e da obtenção de cinco avaliações de desempenho individual satisfatórias. Poderá haver promoção ou progressão aos níveis mais elevados da carreira por escolaridade adicional,conforme prevê o $\S 2^{\circ}$ do art. 18:

$\S 2^{\circ}$ - Haverá progressão ou promoção por escolaridade adicional, após aprovação da Câmara de Coordenação-Geral, Planejamento, Gestão e Finanças, nos termos de decreto, aplicando-se fator de redução ou supressão do interstício necessário e do quantitativo de avaliações periódicas de desempenho individual satisfatórias para fins de progressão ou promoção, na hipótese de formação complementar ou superior àquela exigida para o nível em que o servidor estiver posicionado, desde que relacionada com a natureza e a complexidade da respectiva carreira. (MINAS GERRAIS, 2004).

O posicionamento do servidor no nível para o qual foi promovido se dará no primeiro grau cujo vencimento básico seja superior ao recebido pelo servidor no momento da promoção.

A mais importante alteração da Lei n. 15.293/04 é a vinculação da progressão e da promoção à avaliação de desempenho. Esta não é específica para os servidores da educação, mas é parte constitutiva do paradigma administrativo adotado pela administração que assumiu o poder em 2003. Naquele ano, foi aprovada a Emenda à Constituição de Minas Gerais n.57, de 15 de julho de 2003, que definiu, no art. 17, a avaliação de desempenho:

Art. $3^{\circ}$ - O art. 31 da Constituição do Estado passa a vigorar com a redação que segue: art. 31 - O Estado assegurará ao servidor público civil da Administração Pública direta, autárquica e fundacional os direitos previstos no art. $7^{\circ}, \mathrm{IV}, \mathrm{VII}$, VIII, IX, XII, XIII, XV, XVI, XVII, XVIII, XIX, XX, XXII e XXX, da Constituição da República e os que, nos termos da lei, visem à melhoria de sua condição social e da produtividade e da eficiência no serviço público, em especial o prêmio por produtividade e o adicional de desempenho. $\S 1^{\circ}$ - A lei disporá sobre o cálculo e a periodicidade do prêmio por produtividade a que se refere o "caput" deste 
artigo, o qual não se incorporará, em nenhuma hipótese, aos proventos de aposentadoria e pensões a que o servidor fizer jus e cuja concessão dependerá de previsão orçamentária e disponibilidade financeira do Estado.

$\S 2^{\circ}[\ldots]$.

$\S 3^{\circ}$ - Para fins de promoção e progressão nas carreiras será adotado, além dos critérios estabelecidos na legislação pertinente, o sistema de avaliação de desempenho, que será disciplinado em lei, podendo ser prevista pontuação por tempo de serviço. (MINAS GERAIS, 2003a).

O prêmio por produtividade foi regulamentado pela Lei n. 14.694, de 30 de julho de 2003 (MINAS GERAIS, 2003b), que disciplinou, também, o Acordo de Resultados, como aquele celebrado entre dirigentes de órgãos e entidades do Poder Executivo e as autoridades superiores para o cumprimento das metas estabelecidas. A Lei n. 14.694/03 estabeleceu em seu art. $4^{\mathrm{o}}$ :

Art. $4^{\circ} \mathrm{O}$ Acordo de Resultados terá como objetivos fundamentais:

I - aumentar a oferta e melhorar a qualidade dos serviços prestados à sociedade;

II - estimular, valorizar e destacar servidores, dirigentes e órgãos ou entidades que cumpram o seu papel individual, institucional ou social;

III - aperfeiçoar o acompanhamento e o controle de resultados da gestão pública, mediante instrumento caracterizado pela consensualidade, objetividade, responsabilidade e transparência;

IV - fixar metas de desempenho específicas para órgãos e entidades, compatibilizando a atividade desenvolvida com as políticas públicas e os programas governamentais;

$\mathrm{V}$ - dar transparência às ações dos órgãos públicos e facilitar o controle social sobre a atividade administrativa, mediante a divulgação, por meio eletrônico, dos termos de cada acordo e de seus resultados;

VI - aperfeiçoar as relações de cooperação, supervisão e fiscalização entre o acordante e o acordado;

VII - promover o desenvolvimento e a implantação 
de modelos de gestão flexíveis, vinculados ao desempenho institucional, propiciadores do envolvimento dos seus agentes e dirigentes no aperfeiçoamento dos serviços prestados. (MINAS GERAIS, 2003b).

Os recursos para o pagamento dos Acordos de Resultado seriam originados das economias com despesas correntes e da ampliação da arrecadação de receitas. O prêmio por produtividade só poderá ser recebido por servidor ocupante de cargo de provimento efetivo e por detentor de função pública. Estão, portanto, excluídos do prêmio de produtividade os professores contratados temporariamente.

Segundo a Lei n. 14.694/03, o prêmio de produtividade não se incorpora à remuneração nem aos proventos de aposentadoria ou pensão do servidor e não servirá de base de cálculo para outro benefício ou vantagem, nem para a contribuição à seguridade social (MINAS GERAIS, 2003b).

O Acordo de Resultados deve ser realizado entre os dirigentes e os funcionários, a SEPLAG e das demais partes intervenientes. Para isto, foram instituídas Comissões de Acompanhamento e Avaliação pelos dirigentes máximos dos setores e estes foram encarregados de estabelecer os Projetos Estruturadores ou programas prioritários do Plano Plurianual de Ação Governamental de 2003, monitorando, intensivamente, os acordos que também são acompanhados e avaliados pelo Colegiado de Gestão Governamental. A Lei Complementar n. 71, de 30 de julho de 2003, instituiu a avaliação periódica de desempenho individual e estabeleceu a perda de cargo público e de função pública por insuficiência de desempenho. É o que afirma o art. $1^{\mathrm{o}}$ :

Art. $1^{\circ}$ - O servidor estável ocupante de cargo de provimento efetivo e o detentor de função pública, no âmbito da Administração Pública direta, autárquica e fundacional do Poder Executivo, serão submetidos, anualmente, à avaliação de desempenho individual. (MINAS GERAIS, 2003c).

A Resolução Conjunta SEPLAG/SEE n. 7.110, de 06 de julho de 20095',

3 Revoga as Resoluções Conjuntas SEPLAG/SEE n. 5645/2004; n. 5681/2004; n. 5690,/2004; n. 5759/2005; n. $653 / 2005$ e n. $667 / 2005$. 
estabelece a estratégia de Avaliação de Desempenho Individual (ADI) em vigor desde então:

Art. $2^{\circ}$ - O Processo de ADI ocorrerá de $1^{\circ}$ de janeiro a 31 de dezembro do mesmo ano, devendo ser formalizado e instruído com:

I - Plano de Gestão do Desempenho Individual - PGDI;

II - Termo de Avaliação.

$\S 1^{\circ}$ - O Plano de Gestão do Desempenho Individual - PGDI -, elaborado pela chefia imediata e pelo servidor no início do período avaliatório, deve conter registro das metas e ações planejadas para o respectivo período, conforme ANEXO I desta Resolução.

$\S 2^{\circ}$ - O Termo de Avaliação constitui-se de duas partes:

I- Parte I: registro da identificação do servidor, da Comissão de Avaliação, notificação do resultado, síntese da entrevista, proposta de desenvolvimento do servidor e manifestação do representante de Sindicato ou Entidade representativa de classe, conforme ANEXO II desta Resolução.

II- Parte II: Instrumento de Avaliação, contendo os critérios estabelecidos no art. $5^{\circ}$, que deverá ser preenchido no último mês do período avaliatório, contendo o registro do desempenho do servidor avaliado. (MINAS GERAIS, 2009a).

Os critérios de avaliação são especificados no art. $5^{\circ}$ :

Art. $5^{\circ}$ - Os servidores serão avaliados em quatro critérios de avaliação de desempenho e respectivos descritores de competências, com valoração máxima de 100 pontos, da seguinte forma:

I- Desenvolvimento Profissional, cujo somatório dos descritores perfaz um total de quinze pontos; II- Relacionamento Interpessoal, cujo somatório dos descritores perfaz um total de quinze pontos; III- Compromissos Profissional e Institucional, cujo somatório dos descritores perfaz um total de vinte pontos;

IV- Habilidades Técnicas e Profissionais, cujo somatório dos descritores perfaz um total de cinquenta pontos.

Parágrafo único. Para a atribuição da pontuação 
em cada descritor, a Comissão de Avaliação deverá adotar como regra o consenso ou, na falta deste, a média aritmética. (MINAS GERAIS, 2009a).

No decorrer da avaliação, a chefia imediata realiza entrevista com o servidor, acompanha o registro de metas, ações e o resultado da meta, avaliando se o servidor executou, executou parcialmente ou não executou as metas previstas. A Comissão de Avaliação dará o resultado final que será a média dos pontos conseguidos em cada quesito. A Comissão fornecerá o resultado no Termo Final de Avaliação (apto, inapto, infrequente).

A metodologia adotada para o Processo de Avaliação Especial de Desempenho (AED) do estágio probatório é a mesma prevista para a ADI, diferindo apenas quanto ao período de avaliação que, no caso da AED, ocorre em etapas e tem a duração de três anos.

A Comissão de Avaliação é composta por três ou cinco servidores de nível hierárquico superior ao do avaliado, dos quais pelo menos dois contem com, no mínimo, três anos de exercício em cargo de provimento efetivo. O funcionário conta com a Comissão de Recursos para reconsideração da avaliação realizada. Os designados e contratados não avaliam e não são avaliados. O processo de avaliação conta com manifestação do representante de sindicato ou associação dos servidores.

Embora a Lei n. 15.293/04 tenha instituído as carreiras dos profissionais de Educação Básica, ela não tratou dos salários. Assim, os professores continuaram, nos anos seguintes, lutando pela implantação de um Plano de Carreira, Cargos e Salários. Em 2005, o sindicato coordenou mobilizações para que o governo apresentasse as tabelas salariais do plano de carreira aprovado em 2004 e para cobrar os acordos de greve assinados. Diversas mobilizações foram realizadas e, apesar da comissão de negociação ser recebida pela Secretária de Educação, após a ocupação da SEPLAG, não houve negociação ou modificação nas tabelas salariais. A reivindicação mais importante foi o posicionamento automático de todos os servidores, eliminando os prazos exigidos pela SEPLAG para alocar os professores na carreira, conforme sua habilitação.

Em 2005, foi sancionada a Lei n. 15.784 (MINAS GERAIS, 2005) que estabeleceu as tabelas de vencimentos das carreiras dos profissionais 
da Educação Básica e dispôs sobre a Vantagem Transitória Incorporada (VTI) e sobre o posicionamento dos servidores nas respectivas carreiras. Apenas em 2009, o Decreto n. 45.274 (MINAS GERAIS, 2009b) regulamentou o posicionamento dos servidores efetivos incluindo tempo de serviço no enquadramento nas carreiras da Educação Básica.

Para o posicionamento só foi levada em consideração a titulação mínima para ingresso na carreira. $O$ fato de não levar em consideração o tempo de serviço dos professores ocasionou grandes distorções e revelou a fragilidade das negociações sindicais com o governo. Um dos questionamentos à regulamentação da Lei n. 15.293/04 deve-se à subordinação à SEPLAG, pois, com relação ao posicionamento dos profissionais na carreira, a Lei n. 15.784/05 estabeleceu:

Art. $7^{\circ}$ - A lotação dos cargos das carreiras de que trata esta lei nos quadros de pessoal dos órgãos e das entidades a que se refere o art. $5^{\circ}$ será definida em decreto e fica condicionada à anuência das entidades envolvidas e à aprovação da Secretaria de Estado de Planejamento e Gestão - SEPLAG -, observado o interesse da Administração. (MINAS GERAIS, 2005).

A progressão e a promoção, que teriam, pela Lei, que aguardar um período de 5 anos, dependem de avaliação de desempenho e, também, estão submetidas à aprovação da SEPLAG. A progressão por escolaridade adicional é outro dispositivo subordinado à decisão do mesmo Órgão. Além disso, a decisão de permitir o aumento da carga horária depende de decisão conjunta da SEE e da SEPLAG:

$\S 3^{\circ}$ - Os atos de posicionamento a que se refere o "caput" deste artigo serão formalizados por meio de resolução conjunta do Secretário de Estado de Educação e do Secretário de Estado de Planejamento e Gestão. (MINAS GERAIS, 2005).

Em 2005, o salário básico inicial para o professor com habilitação em Magistério, no Nível I, Grau A foi estabelecido em R \$305,00 e para o Professor com Licenciatura Plena ou complementação pedagógica em $\mathrm{R} \$ 453,96$ (TAB. 1): 


\section{TABELA 1}

Vencimentos Professor de Educação Básica -Titulação Ensino Superior Jornada de 24 horas semanais - Minas Gerais - 2005 - 2010

\begin{tabular}{c|c|c|c|c|c}
\hline ANO & $\mathbf{2 0 0 5} \mathbf{( R \$ )}$ & $\mathbf{2 0 0 6}$ & $\mathbf{2 0 0 7}$ & $\mathbf{2 0 0 8}$ & $\mathbf{2 0 0 9}$ \\
\hline $\begin{array}{c}\text { Vencimento } \\
\text { Básico }\end{array}$ & 453,96 & 476,66 & 500,49 & 500,49 & 500,49 \\
\hline $\begin{array}{c}\text { Abonos + } \\
\text { Gratificação }\end{array}$ & $\begin{array}{c}\text { Abonos + } \\
\text { Gratificação }\end{array}$ & $\begin{array}{c}\text { Abonos + } \\
\text { Gratificação }\end{array}$ & $\begin{array}{c}\text { Abonos + } \\
\text { Gratificação }\end{array}$ & $\begin{array}{c}\text { VTI+ } \\
\text { PCRM }\end{array}$ & $\begin{array}{c}\text { VTI+ } \\
\text { PCRM }\end{array}$ \\
\hline $\begin{array}{c}\text { Remuneração } \\
\text { total }\end{array}$ & Variável & Variável & Variável & 850,00 & 935,00 \\
\hline
\end{tabular}

Fonte: SECRETARIA DE ESTADO DE EDUCAÇÃO DE MINAS GERAIS. Nota: Parcela Compensatória Remuneratória do Magistério (PCRM).

Diante das distorções no posicionamento e da baixa remuneração, as negociações do sindicato com a equipe administrativa continuaram. Em maio de 2006, a Secretária de Educação recebeu a direção do Sind-UTE/ MG, informando que o governo editaria um decreto dispondo sobre a antecipação da promoção por escolaridade adicional, decreto este que teve o número 44.291/06. Nas negociações com a administração estadual, o sindicato admitiu o fracasso do aumento salarial, mas reconheceu a importância da promoção por escolaridade adicional, proposta pelo Plano de Carreira e implementada somente em 2006. Em 2007, a mobilização dos professores continuou com greves de 24 horas, inclusive unificadas com o funcionalismo público, realização de Marcha Nacional a Brasília, Semana de Educação e greve nacional pelo piso (Piso Salarial Profissional Nacional). A direção do Sind-UTE/MG foi recebida em várias audiências pela Secretária de Educação do Estado, mas nenhum avanço foi obtido.

Com a aprovação da Lei n. 11.738/08, que instituiu o Piso Salarial Profissional Nacional (PSPN), o valor inicial nacional foi fixado em R\$950,00, para jornada semanal de 40 horas (BRASIL, 2008). Em Minas Gerais, para uma jornada de 24 horas, o valor foi reduzido para $\mathrm{R} \$ 850,00$ com a inclusão de todos os abonos e adicionais existentes. A administração estadual instituiu, para complementar os salários, em 2008, o abono denominado Parcela Compensatória Remuneratória do Magistério 
(PCRM), variável, representando o montante necessário para se atingir a remuneração de $\mathrm{R} \$ 850,00$. Em abril de 2008, durante audiência da Coordenação Intersindical com o vice-governador, foi recolocada a questão do piso salarial pelo Sind-UTE/MG. Foram realizadas audiências na Secretaria de Educação e na SEPLAG, além de assembléias, divulgação na mídia, atos públicos, panfletagens, entre outros. Entretanto, na negociação, não foi apresentada nenhuma contraproposta à reivindicação salarial - piso de R \$950,00 para profissional com formação de nível médio, com jornada de 24 horas/semanais. A atuação do sindicato, a partir de então, não foi apenas uma ação de reivindicação salarial, mas assumiu caráter político de oposição: houve manifestações e ações contra o governo.

Em 2010, o PSPN foi estipulado pelo Governo Federal em R\$1.024,67. Para a Secretaria de Estado de Educação de Minas Gerais, a remuneração dos professores seria de $\mathrm{R} \$ 935,00$, incluindo todos os adicionais. Sindicalistas criticaram o cálculo afirmando que o valor informado pelo Estado estava equivocado. A presidente do Sind-UTE, Beatriz Cerqueira, criticou o critério aprovado afirmando que "ao contrário do que foi divulgado pelo Governador, atualmente temos um teto salarial e não piso salarial" CERQUEIRA, 2010). Entretanto, o discurso oficial reafirmou que não poderia dar aumento ao magistério, reiterando o que já havia sido anunciado em 2003:

O Estado deve imbuir-se efetivamente de uma maior responsabilidade na gestão fiscal, conforme determinado pela Lei Complementar Federal n. ${ }^{\circ}$ 101, de 4 de maio de 2000, buscando corrigir o desequilíbrio de suas contas públicas e reduzir o deficit que ameaça o exercício de suas atividades. Faz-se necessário, pois, impor limites e condições à geração de maiores despesas com pessoal, seguridade social, materiais, dentre outras, bem como à renúncia de receita. (ANASTASIA, 2003).

O Plano de Carreira do Magistério da Educação Básica de Minas Gerais teve curta duração. Em 2010, foi enviada à Assembléia Legislativa, e aprovada, uma modificação do regime jurídico que alterou a remuneração para Subsídio, com vigência a partir de 2011. Assim, a Lei n. 18.975, de 29 de junho de 2010 (MINAS GERAIS, 2010a), regulamentada 
pelo Decreto n. 45.527, de 30 de dezembro de 2010 (MINAS GERAIS, 2010b), alterou a forma de pagamentos instituindo a remuneração por Subsídio e organizou uma nova tabela de posicionamento funcional. O Subsídio é uma remuneração "em parcela única, vedado o acréscimo de qualquer gratificação, adicional, abono, prêmio, verba de representação ou outra espécie remuneratória". Essa espécie de remuneração está prevista no $\S 4^{\circ}$ do art. 39 da Constituição Federal (BRASIL, 1988), possibilitada aos servidores públicos em carreira. Nessa ocasião, a presidente do Sind-UTE criticou: “[...] pela Lei n. 18.975/10, não é Piso Salarial, é total de remuneração que descaracteriza o que cada servidor conquistou ao longo da sua vida funcional" (SINDICATO ÚNICO DOS TRABALHADORES EM EDUCAÇÃO DE MINAS GERAIS, 2011a).

Os valores fixados no pagamento do Subsídio incorporam, para o cargo de Professor da Educação Básica, do regime remuneratório anterior, o vencimento básico, a gratificação de incentivo a docência, a gratificação de educação especial, as gratificações por cursos de pós-graduação e a gratificação por regime especial de trabalho. Além dessas, outras parcelas comuns a todos os cargos foram incorporadas, tais como adicionais por tempo de serviço, vantagens pessoais para servidor apostilado, auxílio-alimentação, adicional de desempenho, vantagens pessoais para servidores do Minas Caixa absorvidos para a administração direta, vantagem temporária incorporável (VTI); parcela de complementação remuneratória do magistério (PCRM); auxíliotransporte e vantagens pessoais por adicional por tempo de serviço (MINAS GERAIS, 2010a).

A nova tabela para o cargo de Professor de Educação Básica passou, a partir da edição da Lei n. 18.975/10, a ter a seguinte configuração: 
TABELA 2

Carreira de Professor de Educação Básica da Lei n. 18.975/10

\begin{tabular}{c|c|c}
\cline { 2 - 3 } & \multicolumn{2}{|c}{ PROFESSOR DE EDUCAÇÃO BÁSICA } \\
\hline Sigla & Niveis & Graus \\
\hline PEB T1 & Ensino Médio (em extinção) & A a P \\
PEB T2 & Licenciatura Curta (em extinção) & A a P \\
PEB I & Licenciatura Plena & A a P \\
PEB II & Especialização & A a P \\
PEB III & Certificação & A a P \\
PEB IV & Mestrado & A a P \\
PEB V & Doutorado & A a P \\
\hline
\end{tabular}

Fonte: Anexo I da Lei n. 18.975/10.

Para todos os efeitos, os antigos aumentos por biênios e qüinqüênios são perdidos, pois o enquadramento, na grande maioria dos cargos, para os servidores com longos anos de serviço, se deu no Nível I, Grau A (com formação em Licenciatura Plena), recebendo como professores recém-nomeados, efetivados e designados na rede.

O Sind-UTE/MG entendeu que, naquele momento, o Subsídio representaria uma conquista em termos de vencimentos para a categoria que se encontrava com baixo poder de compra tendo em vista a paulatina desvalorização sofrida ao longo da última década (SINDICATO ÚNICO DOS TRABALHADORES EM EDUCAÇÃO DE MINAS GERAIS, 2011b).

A Lei n. 18.975/10, fruto de um processo de lutas por melhores condições remunerativas, trouxe para o cenário educacional a política do Subsídio, com conteúdos e mudanças pouco expressivas, principalmente para os profissionais efetivos e com mais tempo de função, além da não elevação do vencimento base em comparação com a Lei n. 11.738/08.

\section{Considerações finais}

Nesta pesquisa, foi constatada a tensão existente na correlação de forças entre a ação estatal e o movimento dos trabalhadores da educação na regulação das relações de trabalho e na definição da política de remuneração e do tempo de trabalho. Em lugar de uma 
conclusão, foram levantadas várias questões que resultaram da análise da teoria e da história dos movimentos sindicais no Brasil. A primeira questão interroga em que medida o contexto político e, principalmente, as políticas públicas estaduais podem descaracterizar a carreira dos profissionais da educação, resultando não em valorização, mas em recuo nas conquistas de direitos. A segunda busca compreender em que medida a subordinação da valorização do magistério ao ajuste fiscal afeta os professores, colocando em primeiro plano a restrição salarial e, em particular, condicionando o Plano de Carreira e a sua implantação às diretrizes de uma política administrativa que submete a política educacional à lógica da administração gerencial orientada pela eficiência em detrimento dos princípios constitucionais de valorização do magistério. 


\section{Referências}

ABRUCIO, Fernando Luiz. Reforma do Estado e federalismo: o caso dos governos estaduais brasileiros. p.1-38, 2008. Disponível em: <http:// info.worldbank.org/etools/docs/library/229649/Abrucio.pdf>. Acesso em: 10 ago. 2010.

ANASTASIA, Antônio Augusto Junho. Os desdobramentos do choque de gestão de Minas Gerais. Revista Governança e Desenvolvimento, Brasília, n.1, p. 16-22, 2003.

ANDRADE, Nilton de Aquino. Os efeitos da Lei de Responsabilidade Fiscal nas finanças dos municípios mineiros. 2006. Dissertação (mestrado) - Fundação Visconde de Cairú, Faculdade de Ciências Contábeis, Centro de Pós-graduação e Pesquisa, Salvador.

ARELARO, Lisete Regina; GIL, Juca. Política de fundos na educação: duas posições. In: LIMA, Maria José rocha; DIDONET, Vital (Orgs.) FUNDEB: avanços na universalização da educação básica. Brasília: Inep, 2006, p. 71-88.

BALZANO, Sônia. Estudos dos planos de carreira e remuneração do magistério da educação básica dos estados brasileiros. Consed/Rh: Brasília, 2005.

BRASIL. Constituição (1988). Constituição da República Federativa do Brasil. Disponível em:<http:/ / www.presidencia.gov.br>. Acesso em: 02 nov. 2010.

BRASIL. Lei n. 9.424 de 24 de dezembro de 1996. Dispõe sobre o Fundo de Manutenção e Desenvolvimento do Ensino Fundamental e de Valorização do Magistério, e dá outras providências. Diário Oficial da União, Brasília, n. 250, 26 dez. 1996. 
BRASIL. Ministério da Educação. Conselho Nacional de Educação. Resolução n. 3 de 8 de outubro de 1997. Fixa Diretrizes para os Novos Planos de Carreira e de Remuneração para o Magistério dos Estados, do Distrito Federal e dos Municípios. Disponível em <http:/ /www. portal.mec.gov.br/cne/arquivos>. Acesso em: 02 out. 2011.

BRASIL. Lei Complementar n. 101 de 4 de maio de 2000. Lei de Responsabilidade Fiscal. Estabelece normas gerais de direito financeiro para elaboração dos orçamentos e balanços da União, dos Estados, dos Municípios e do Distrito Federal. Disponível em: <http://www. presidência. gov.br>. Acesso em: 10 nov. 2010.

BRASIL. Lei n. 11.494 de 20 de junho de 2007. Dispõe sobre o Fundo de Manutenção e Desenvolvimento da Educação Básica e de Valorização dos Profissionais da Educação, na forma prevista no artigo 60, do Ato das Disposições Constitucionais Transitórias. Diário Oficial da União, Brasília, 21 jun. 2007.

BRASIL. Lei n. 11.738 de 16 de julho de 2008. Regulamenta a alínea " $\mathrm{e}$ " do inciso III do caput do art.6 $6^{\circ}$ do Ato das Disposições Constitucionais Provisórias, para instituir o piso salarial profissional nacional para os profissionais do magistério público da educação básica. Diário Oficial da União. Brasília, n. 136, 17 jul. 2008. Seção 1, p.1.

BRASIL. Proposta de Emenda Constitucional do Fundeb n. 415 de junho de 2005. Disponível em: <http:/ / www.planalto.gov.br/ccivil htm>. Acesso em: 18 ago. 2010.

BRITO, Vera Lúcia. Os ajustes fiscais da última década em Minas Gerais e a remuneração dos professores In: Encontro Nacional do Observatório da Remuneração Docente, I, 2011, São Paulo.

CERQUEIRA, Beatriz. Professores da rede estadual decidem continuar em greve. Jornal O Tempo, Belo Horizonte, 15 abr. 2010. 


\section{CONFEDERAÇÃO NACIONAL DOS TRABALHADORES EM} EDUCAÇÃO. CNTE notícias. Brasília, out. 2007. Disponível em: <http:/ / www.cnte.org.br>. Acesso em 07 ago. 2010.

DAVIS, N. O Fundef e o orçamento da educação: desvendando a caixa preta. Campinas: Autores Associados, 1999.

. Fundef: Um breve balanço não oficial. Contexto $\mathcal{E}$ Educação, ano XV, n. 57, Ijuí, RGS, 2000, p. 121-126.

O Tribunal de Contas de Minas e sua eficácia na avaliação dos gastos governamentais em educação. Revista Educação em Foco, UFJF, 2001.

DINIZ, Eli. Crise, reforma do Estado e governabilidade: Brasil, 1985-95. Rio de Janeiro: Editora FGV, p. 175-202, 1997.

DINIZ, Eli; AZEVEDO, Sérgio. Governabilidade, democracia e reforma do Estado: os desafios da construção de uma nova ordem no Brasil dos anos 90. In: AZEVEDO, Sérgio. Reforma do Estado e democracia no Brasil: dilemas e perspectivas. Brasília: Editoria Universidade de Brasília, 1997.

GREGGIANIN, Eugênio. Lei de Responsabilidade Fiscal. Aspectos Críticos. Responsabilidade na gestão pública: os desafios dos municípios. Brasília: Câmara dos Deputados, ed. Câmara, 2008. Série avaliação de políticas públicas; n.2, p; 195-267.

JAYME JR, F. G.; REIS, Júlio César dos; ROMERO, João Prates. Restrição orçamentária e Lei de Responsabilidade Fiscal: um estudo para Minas Gerais (1995-2006). Ensaios FEE, v. 28, p. 5-25, 2007.

MINAS GERAIS. Emenda à Constituição n. 57 de 15 de julho de 2003a. Altera os arts. $14,25,31,39,125$ e 290 e revoga os $\S \S 1^{\circ}$ e $2^{\circ}$ do art. 32 
da Constituição do Estado e acrescenta os arts. 112 a 121 ao Ato das Disposições Constitucionais Transitórias. Disponível em: <http:/ / crv. educacao.mg.gov.br/sistema_crv/banco_objetos_crv/\%7BDF7820405F4D-4969-B497-8FF27B64A0A3\%7D_emenda\%20constituicao \%20 57\%202003.pdf >. Acesso em: 12 maio 2011.

MINAS GERAIS. Lei n. 14.694 de 30 de julho de 2003b. Disciplina a avaliação de desempenho institucional, o Acordo de Resultados, a autonomia gerencial, orçamentária e financeira, a aplicação de recursos orçamentários provenientes de economias com despesas correntes no âmbito do Poder Executivo e dá outras providências. Disponível em: < http://www.fazenda.mg.gov.br/servidores/avaliacao_desempenho/ legislacao/lei_14694.html>. Acesso em: 12 maio 2011.

MINAS GERAIS. Lei Complementar n. 71 de 30 de julho de 2003c. Institui a avaliação periódica de desempenho individual, disciplina a perda de cargo público e de função pública por insuficiência de desempenho do servidor público estável e do detentor de função pública na Administração Pública direta, autárquica e fundacional do Poder Executivo e dá outras providências. Disponível em: <http:/ / www.educacao.mg.gov.br/weblaf/index>. Acesso em: 12 maio 2011.

MINAS GERAIS. Lei n. 15.293 de 05 de agosto de 2004. Institui as carreiras dos Profissionais de Educação Básica do Estado. Disponível em: <http:/ / www.crv.educacao.mg.gov.br>. Acesso em: 13 fev. 2012.

MINAS GERAIS. Lei n. 15.784 de 27 de outubro de 2005. Estabelece as tabelas de vencimento básico das carreiras dos Profissionais de Educação Básica e das carreiras do Grupo de Atividades de Defesa Social, a que se referem os incisos VII a XI do art. $1^{\circ}$ da Lei n. 15.301, de 10 de agosto de 2004, os seus reajustamentos e dispõe sobre a Vantagem Temporária Incorporável - VTI - e o posicionamento dos servidores nas referidas carreiras. Disponível em: <http:/ / www.crv. educacao.mg.gov.br>. Acesso em: 10 jun. 2011. 
MINAS GERAIS. Resolução Conjunta SEPLAG/SEE n. 7.110 de 06 de julho de 2009a. Define metodologia de Avaliação de Desempenho Individual - ADI- e Avaliação Especial de Desempenho - AED - dos servidores em exercício na Secretaria de Estado de Educação de Minas Gerais. Disponível em: <http:// www.planejamento.mg.gov.br>. Acesso em: 20 out. 2011.

MINAS GERAIS. Decreto n. 45.274 de 30 de dezembro de 2009b. Regulamenta o reposicionamento por tempo de serviço nas carreiras do Poder Executivo Estadual. Disponível em: <http:// www. planejamento.mg.gov.br/servidor/planos>. Acesso em: 20 set. 2011.

MINAS GERAIS. Lei n. 18.975 de 29 de junho de 2010. Fixa os subsídios das carreiras dos Grupos de Atividade de Educação Básica do Poder Executivo Estadual e do pessoal civil da Polícia Militar do Estado de Minas Gerais e dá outras providências. Minas Gerais - Diário do Executivo. Belo Horizonte: Imprensa Oficial, 2010a.

MINAS GERAIS. Decreto n. 45.527 de 31 de dezembro de 2010. Regulamenta a Lei n. 18.975, de 29 de junho de 2010. Minas Gerais Diário do Executivo. Belo Horizonte: Imprensa Oficial, $2010 \mathrm{~b}$.

MINAS GERAIS. Relatório do Grupo de Trabalho Instituído pela Resolução Conjunta n. 7559 de 27 de maio de 2010. Belo Horizonte: SEE e SEPLAG, 2010c.

MINAS GERAIS. Tribunal de Contas. Relatório Técnico: Prestação de Contas do Governador do Estado de Minas Gerais exercício de 2003; 2004; 2005; 2006; 2007; 2008; 2009; 2010. Disponível em: <http:// www.tcemg.gov.br>. Acesso em: 05 mar. 2012.

OLIVEIRA, Fabrício Augusto. Teorias da Federação e do Federalismo fiscal: o caso brasileiro. FJP: Texto para discussão n. 43. Belo Horizonte, 2007. 
REIS, André Abreu. Avaliação das contas do governo do Estado de Minas Gerais de 1995 a 2005: uma busca de iniciativas de ajuste fiscal. 2006. Dissertação (Mestrado). - Escola de Governo/ Fundação João Pinheiro, Belo Horizonte.

RIANI, Flávio. Limitações e conseqüências do ajuste fiscal do Estado de Minas Gerais no Governo Aécio Neves, 2004.

SINDICATO ÚNICO DOS TRABALHADORES EM EDUCAÇÃO DE MINAS GERAIS. INFORMA n. 29, Belo Horizonte: Departamento de Comunicação Sind-UTE/MG, 2011a.

. INFORMA n. 24. Belo Horizonte: Departamento de Comunicação Sind-UTE/MG, 2011b.

. INFORMA n. 31. Belo Horizonte: Departamento de Comunicação Sind-UTE/MG, 2011c.

. Nossa História. Disponível em: <http://www.sindutemg.org. br/novosite/conteudo.php?>. Acesso em: 09 abr. 2012. 


\title{
Career plan for basic education in Minas Gerais: professional development?
}

\begin{abstract}
The study aims to analyze the policies on education in the Brazilian context and the configuration and development of teaching career of basic education in the State of Minas Gerais. On the basis of legal frameworks and career plan will be investigating the teacher's valorization policies of these professionals in the State. The career plan of education professionals was created by law number 15.293 promulgated in 2004 and includes classes and levels that allow knowing the career structure. In 2010 the law n. 18.975 fixed the remuneration of professionals of basic education in the form of subsidy which prohibits the addition of any additional allowance, bonus, award, grant of representation or other species remuneration. The teachers ' career plan will be reviewed under the perspective of managerial administration in the State of Minas Gerais called shock management governance. The research is situated in the context of $\mathrm{t}$ of public policies for education financing.
\end{abstract}

Keywords: educational policies; Remuneration of teachers; legislation.

Recebido: 18/01/2012

Aprovado: 27/06/2012 